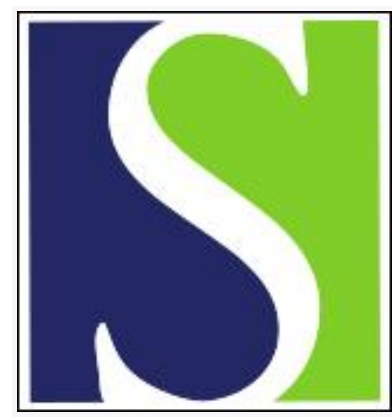

Scand J Work Environ Health 2014;40(1):74-81

https://doi.org/10.5271/sjweh.3382

Published online: 12 Sep 2013, Issue date: 01 Jan 2014

Patient transfers and assistive devices: prospective cohort study on the risk for occupational back injury among healthcare workers

by Andersen LL, Burdorf A, Fallentin N, Persson R, Jakobsen MD, Mortensen OS, Clausen T, Holtermann A

The majority of previous studies on occupational back injury draw on data from US, Canadian, or Australian care facilities or insurance companies. This prospective cohort study among more than 5000 Danish healthcare workers shows that daily patient transfers increase the risk for occupational back injury, and that persistent use of assistive devices confers a protective effect.

Affiliation: National Research Centre for the Working Environment, Lersø Parkalle 105, DK 2100 Copenhagen Ø, Denmark. Ila@nrcwe.dk

Refers to the following texts of the Journal: 2013;39(2):164-169

2013;39(1):27-36 1998;24(5):367-375

The following articles refer to this text: 2015;41(2):153-163;

2016;42(6):510-519; 2019;45(2):146-157

Key terms: assistive device; back; back injury; cohort study; eldercare worker; ergonomics; healthcare worker; longitudinal; low-back pain; musculoskeletal disorder; nurse; occupational risk factor; patient transfer; prospective cohort study

This article in PubMed: www.ncbi.nlm.nih.gov/pubmed/24030699 


\title{
Patient transfers and assistive devices: prospective cohort study on the risk for occupational back injury among healthcare workers
}

\author{
by Lars L Andersen, PhD, ${ }^{1}$ Alex Burdorf, PhD, ${ }^{2}$ Nils Fallentin, PhD, ${ }^{3}$ Roger Persson, PhD, ${ }^{4}$ Markus D \\ Jakobsen, MSc, ${ }^{1}$ Ole S Mortensen, PhD,,$^{1,5}$ Thomas Clausen, PhD, ${ }^{1}$ Andreas Holtermann, PhD ${ }^{1}$
}

\begin{abstract}
Andersen LL, Burdorf A, Fallentin N, Persson R, Jakobsen MD, Mortensen OS, Clausen T, Holtermann A. Patient transfers and assistive devices: prospective cohort study on the risk for occupational back injury among healthcare workers. Scand J Work Environ Health. 2014;40(1):74-81. doi:10.5271/sjweh.3382
\end{abstract}

\begin{abstract}
Objectives This prospective cohort study investigates work-related risk factors for occupational back injury among healthcare workers.

Methods The study comprised 5017 female healthcare workers in eldercare from 36 municipalities in Denmark who responded to a baseline and follow-up questionnaire in 2005 and 2006, respectively. Using logistic regression, the odds for occupational back injury (ie, sudden onset episodes) in 2006 from patient transfers in 2005 was modeled.
\end{abstract}

Results In the total study population, $3.9 \%$ experienced back injury during follow-up, of which $0.5 \%$ were recurrent events. When adjusting for lifestyle (body mass index, leisure-time physical activity, smoking), workrelated characteristics (seniority and perceived influence at work), and history of back pain and injury, daily patient transfers increased the risk for back injury (trend, $\mathrm{P}=0.03$ ): odds ratio $(\mathrm{OR}) 1.75$ [95\% confidence interval (95\% CI) 1.05-2.93] for 1-2 transfers per day, OR 1.81 (95\% CI 1.14-2.85) for 3-10 transfers per day, and OR $1.56(95 \%$ CI $0.96-2.54)$ for $>10$ transfers per day, referencing those with $<1$ patient transfer on average per day. The population attributable fraction of daily patient transfer for back injury was estimated to be $36 \%$. Among those with daily patient transfer $(\mathrm{N}=3820)$, using an assistive device decreased the risk for back injury for "often" and "very often" use [OR 0.59 (95\% CI 0.36-0.98) and OR 0.62 (95\% CI 0.38-1.00), respectively] referencing those who "seldom" use assistive devices.

Conclusion Daily patient transfer was associated with increased risk for back injury among healthcare workers. Persistent use of an assistive device was associated with reduced risk for back injury among healthcare workers with daily patient transfers.

Key terms eldercare worker; ergonomics; longitudinal; low-back pain; musculoskeletal disorder; nurse; occupational risk factor.

The direct and indirect costs associated with occupational injuries in the healthcare sector are substantial. In the US, healthcare workers injury rates equal or exceed rates in other industries that are traditionally considered hazardous (1). In Europe, the proportion of healthcare workers who consider their health and safety to be at risk due to their work is higher than the average across all sectors in the EU (2).

Musculoskeletal injuries and disorders, especially related to patient-handling tasks, significantly contribute to the high burden of work-related injuries and disorders among nurses and aides in hospitals and nursing homes (3). According to the US Bureau of Labor Statistics, non-fatal occupational injuries among healthcare workers resulted in 283 lost workdays per 10000 full-time workers in 2010 (4). A majority of injuries are attributable to overexertion and primarily affect the back. The costs of such injuries - both to the individual and to society - are high. For the individual the result is often long-term adverse physical and psychological consequences (5) and

1 National Research Centre for the Working Environment, Copenhagen Ø, Denmark.

2 Department of Public Health, Erasmus MC, Rotterdam, the Netherlands.

3 Liberty Mutual Research Institute for Safety, Hopkinton, Massachusetts, USA.

4 Department of Psychology, Lund University, Lund, Sweden.

5 Department of Occupational Medicine, Køge Hospital, Køge, Denmark.

Correspondence to: Lars L Andersen, National Research Centre for the Working Environment, Lersø Parkalle 105, DK 2100 Copenhagen Ø, Denmark. [E-mail: 1la@nrcwe.dk] 
from a societal point of view the economic burden associated with overexertion injuries threatens the quality and sustainability of an already struggling healthcare sector.

The association between specific workplace risk factors (manual handling and transferring of patients) and the incidence of low-back injuries has been demonstrated in a large number of studies (6-9). This is not surprising since biomechanical studies have demonstrated how low backloads during common patient handling tasks frequently exceed recommended safe limits for maximal acceptable compressive forces on the back $(10,11)$. The problem is further aggravated because, when first initiated, a history of back pain or injury is associated with recurrent back injury (12-14), which is often more severe and costly than the initial episode $(12,14)$.

Intervention studies using pre-post designs have identified factors associated with reduced risk for back injury (15-17). An Australian study observed a reduced number of back injury claims across an entire healthcare system after introducing a "no lifting" policy [eg, by using appropriate assistive device during patient transfer (15)]. Schoenfish and coworkers (16) evaluated the effect of a "minimal manual lifting" policy in combination with the implementation of an assistive lifting device in two large healthcare workplaces: a community hospital and medical center. While the authors reported a $44 \%$ reduction of musculoskeletal injuries related to patient transfer in the hospital, no such effect was evident at the medical center. In response to a participatory ergonomics program, Garg and coworkers (17) found a $60 \%$ reduction of injuries related to patient transfer across six long-term care facilities and one chronic care hospital (17).

Altogether, the majority of previous studies on occupational back injury draw on data from US, Canadian, or Australian care facilities or insurance companies. However, results from one country may not be directly transferred to other countries due to the differences in, for example, culture, education, physical and psychosocial work environment, and types of available assistive devices. Thus, the aim of our prospective cohort study among 5017 healthcare workers in eldercare in Denmark was to (i) estimate the risk for occupational back injuries from patient transfers, and (ii) evaluate whether the use of an assistive device during patient transfer is associated with reduced occurrence of back injuries.

\section{Methods}

\section{Study design and population}

This prospective cohort study comprised healthcare workers in eldercare from 36 municipalities in Denmark.
The baseline survey started in the winter of 2004, but the main data collection took place in the spring of 2005. Data collection for follow-up was, for the most part, conducted in the autumn of 2006 but continued up to the spring of 2007. At baseline, questionnaires were sent to 12744 workers from the healthcare sector. Of these potential respondents, 9949 (78\%) completed the questionnaire. One municipality decided to withdraw from the cohort during the follow-up period due to a lack of employee support for taking part in the followup study. Hence, the follow-up population consisted of 9847 employees from 327 individual workplaces in the eldercare services. Of these, 1983 no longer worked in the eldercare services in the participating municipalities. This implies that 7864 were eligible for the follow-up questionnaire in 2006, of which 6307 responded (80\%). Next, we excluded male respondents $(\mathrm{N}=234)$ and respondents who were not directly engaged in the provision of care services $(\mathrm{N}=1021)$. Thus, only the 5052 female healthcare workers who responded to both questionnaires and were directly engaged in the provision of health-related care services in the Danish eldercare sector were included. This comprised social and healthcare assistants, social and healthcare helpers, other care staff with no or short-term education and registered nurses/ therapists. Due to missing questionnaire replies, the data set consisted of 5017 responses regarding the questions about back injury and working conditions.

\section{Ethical approval and confidentiality}

The Danish Data Protection Agency was notified of and registered the study. According to Danish law, questionnaire- and register-based studies need neither approval from ethical and scientific committees nor informed consent $(18,19)$. Nevertheless, prior to data collection, we held informational meetings at the participating workplaces. Additionally, respondents received a letter describing the aims of the study, instructions about the response process, and details about confidentiality. Finally, we set up a telephone hotline that respondents could call for clarification of any uncertainties pertaining to the study. All data was de-identified and analyzed anonymously.

\section{Predictive variables}

Frequency of patient-handing activities was evaluated with the question: "Do you perform transfers of patients (lifting) or similar activities during your daily work?", with response options: "no, never", "seldom", "1-2 times daily", "3-10 times daily" "> 10 times daily" (20). In the analyses, the response categories "No, never" and "seldom" were combined and defined as "less than once daily" and used as a reference. 
History of back trouble at baseline was evaluated by asking about previous back injury and duration of back pain. Previous back injury was evaluated with the question: "Have you injured your low back in an accident at work during the last 12 months (an accident is a sudden and unexpected event)" with the response categories yes/no. The standardized Nordic questionnaire (21) was used to evaluate the duration of back pain during the previous year.

Use of an assistive device during patient transfers was evaluated with the question: "Do you use assistive (lifting) devices when you lift or move a patient?" with the response options: "no, never", "seldom", "sometimes", "often", and "very often" (20). The first two response options were rarely used, thus for subsequent analyses, the options "no, never", "seldom", and "sometimes" were collapsed and termed "sometimes" in the analyses and used as reference.

Transferring patients alone as opposed to with another healthcare worker was evaluated with the question: "Do you lift or transfer a patient by yourself, even when the job requires two healthcare workers?" with the response options: "no, never" (reference), "seldom", "sometimes", "often", and "very often". The last two response options were rarely used, thus for subsequent analyses, the options "sometimes", "often", and "very often" were collapsed and termed "sometimes" in the analyses.

\section{Outcome}

Back injury during follow-up was evaluated by the question "Have you injured your low back in an accident at work during the last 12 months (an accident is a sudden and unexpected event)" with the response categories yes/no.

\section{Confounders}

Potential confounders from the baseline questionnaire included age (continuous variable), back injury during the previous year (yes/no), body mass index (BMI) (kg/ $\mathrm{m}^{2}$, continuous variable), smoking status (dichotomous variable depicting smoker/non-smoker), leisure-time physical activity (4-categories from low to a very high level) $(22,23)$, seniority (years working as healthcare worker, continuous variable), and influence at work from the Copenhagen Psychosocial Questionnaire (COPSOQ normalized on a $0-100$ scale according to the test score manual) $(24,25)$.

\section{Statistical analysis}

Using logistic regression analysis with random effects modeling, we estimated the risk for back injury during follow-up. All analyses were adjusted for random effects at the workplace level using the "repeated subject" option of PROC GENMOD (SAS version 9.2, SAS Institute, Cary, NC, USA). Results are given as odds ratios (OR) and 95\% confidence intervals (95\% CI).

The first set of analyses included the total cohort. Frequency of patient transfer at baseline was used as a predictive variable for back injury during follow-up. In Model 1, we adjusted the analyses for age and lifestyle factors (BMI, smoking, and leisure physical activity). In Model 2, we additionally adjusted for other work-related factors (seniority and perceived influence at work). Finally, in Model 3, we additionally included history of back trouble (previous back injury and duration of back pain during the previous year at baseline).

The second set of analyses included only those with daily patient transfers ( $\geq 1$ per day). Use of assistive devices and transferring patients alone at baseline were used as predictive variables for back injury during follow-up. In model 1 , we adjusted the analyses for age, life-style factors (BMI, smoking, and leisure-time physical activity), and frequency of patient transfers. In model 2, we additionally adjusted for other work-related factors (seniority and perceived influence at work). Finally, in model 3, we additionally included history of back trouble (previous back injury and duration of back pain during the previous year at baseline)

\section{Results}

Table 1 shows descriptive statistics for the main study variables. Among the cohort of 5017 healthcare workers, $3.9 \%$ experienced a back injury during follow-up, of which $0.5 \%$ were recurrences and $3.4 \%$ new incidences. This number was higher among those with daily patient transfer $(5.0 \%)$ than those with transfers less than once per day $(3.2 \%)$. Healthcare workers performing daily patient transfers were more often smokers and reported lower influence at work compared with workers performing transfers less than once per day.

Table 2 summarizes the OR for back injury during follow-up from 1-2, 3-10, and $>10$ patient transfers per day, referencing those with $<1$ transfer per day. When adjusting for age and lifestyle (model 1), daily patient transfer ( $\geq 1$ per day) was a risk factor for sustaining back injury. The overall estimates for $\geq 3$ transfers per day decreased slightly when adjusting for other workrelated factors (model 2). In the final model (model 3 ), back pain for $>30$ days during the last year and back injury at baseline were significant risk factors for back injury at follow-up, and the estimates for $\geq 3$ transfers per day decreased slightly again, and was only borderline significant for $>10$ transfers per day. By including 
Table 1. Demographics, leisure- and work-related characteristics of the total cohort $(\mathrm{N}=5017)$, healthcare workers with seldom $(\mathrm{N}=1187)$ and daily patient transfer $(\mathrm{N}=3830)$. [SD=standard deviation.]

\begin{tabular}{|c|c|c|c|c|c|c|c|c|c|}
\hline & \multicolumn{3}{|c|}{$\begin{array}{c}\text { All } \\
(\mathrm{N}=5017)\end{array}$} & \multicolumn{3}{|c|}{$\begin{array}{l}\text { Less than once per day } \\
\text { patient transfer }(N=1187)\end{array}$} & \multicolumn{3}{|c|}{$\begin{array}{c}\text { Daily patient } \\
\text { transfer }(\mathrm{N}=3830)\end{array}$} \\
\hline & Mean & SD & $\%$ a & Mean & SD & $\%{ }^{\text {a }}$ & Mean & SD & $\%$ a \\
\hline Age (years) & 46 & 9 & & 46 & 9 & & 46 & 9 & \\
\hline Back injury - baseline & & & 4.6 & & & 3.2 & & & 5.0 \\
\hline Back injury - follow-up & & & 3.9 & & & 2.2 & & & 4.4 \\
\hline Incidence & & & 3.4 & & & 2.2 & & & 3.8 \\
\hline Recurrence & & & 0.5 & & & 0.0 & & & 0.6 \\
\hline \multicolumn{10}{|c|}{ Back pain duration previous year } \\
\hline 0 days & & & 31.2 & & & 36.1 & & & 29.5 \\
\hline $1-30$ days & & & 46.6 & & & 44.7 & & & 47.2 \\
\hline$>30$ days & & & 22.3 & & & 19.2 & & & 23.3 \\
\hline Smoker & & & 35.5 & & & 29.1 & & & 37.6 \\
\hline Body mass index & 25 & 4 & & 25 & 4 & & 25 & 4 & \\
\hline \multicolumn{10}{|c|}{ Leisure-time physical activity } \\
\hline Low & & & 3.7 & & & 3.9 & & & 3.6 \\
\hline Medium & & & 41.0 & & & 42.1 & & & 40.7 \\
\hline High & & & 50.9 & & & 49.5 & & & 51.3 \\
\hline Very high & & & 4.4 & & & 4.5 & & & 4.4 \\
\hline Tenure (years) & 9 & 7 & & 8 & 7 & & 9 & 7 & \\
\hline Influence at work $(0-100)$ & 46 & 20 & & 49 & 20 & & 44 & 20 & \\
\hline \multicolumn{10}{|l|}{ Using assistive device ${ }^{b}$} \\
\hline Never & & & 1.8 & & & 6.1 & & & 0.7 \\
\hline Seldom & & & 6.8 & & & 22.2 & & & 3.1 \\
\hline Sometimes & & & 18.5 & & & 25.5 & & & 16.8 \\
\hline Often & & & 28.7 & & & 19.4 & & & 30.8 \\
\hline Very often & & & 44.3 & & & 26.7 & & & 48.5 \\
\hline \multicolumn{10}{|l|}{ Transferring patients alone ${ }^{b}$} \\
\hline Never & & & 35.1 & & & 50.9 & & & 31.2 \\
\hline Seldom & & & 34.1 & & & 37.2 & & & 33.3 \\
\hline Sometimes & & & 24.6 & & & 10.5 & & & 27.9 \\
\hline Often & & & 4.6 & & & 1.0 & & & 5.5 \\
\hline Very often & & & 1.7 & & & 0.3 & & & 2.1 \\
\hline
\end{tabular}

a Refers to percentage of study population.

b In the second column, those who replied "never" to frequency of patient transfer did not reply to this question.

daily patient transfer as a continuous variable, a trend test showed a significant positive association between frequency of daily patient transfer at baseline and risk of back injury at follow-up (model 1: $\mathrm{P}<0.001$, model 2: $\mathrm{P}<0.01$, model 3: $\mathrm{P}=0.03$ ). In models $1-3$, the attributable fractions, $\mathrm{PAF}=\sum \mathrm{p}_{\mathrm{i}}\left(\mathrm{OR}_{\mathrm{i}}-1\right) /\left[\sum \mathrm{p}_{\mathrm{i}}\left(\mathrm{OR}_{\mathrm{i}}-1\right)+\right.$ $1]$, of daily patient transfer for the risk of back injury were $41 \%, 38 \%$, and $36 \%$, respectively.

Table 3 summarizes the OR for back injury during follow-up from the use of assistive devices and transferring patients alone among those with daily patient transfer. In the first model adjusting for age, lifestyle factors, and frequency of patients transfer, the risk for back injury was lower among those who persistently ("often" and "very often") used an assistive device, referencing those who sometimes used such a device. These findings remained when adjusting for other work-related factors (model 2) and history of back trouble (model 3). The odds for back injury were not higher among those who "seldom" or "sometimes" transferred patients alone, referencing those who never transferred patients alone.

\section{Discussion}

Our study among 5017 Danish healthcare workers in eldercare showed that daily patient transfer was a risk factor for back injury. History of back pain and back injury was associated with increased risk for back injury during follow-up, although recurrences were rare. Importantly, persistent use of assistive devices was associated with reduced risk of back injury in this occupational group.

\section{Occurrence of back injury}

In this study, approximately $5 \%$ of the healthcare workers experienced back injury at work during the previous year. Compared with data from the US, Australia, and Canada, which often report yearly prevalences of musculoskeletal injuries $>20 \%$, this number seems quite low (15-17), even though within the US there are large differences in injury claims across studies (26). Such differences may to a large 
Table 2. Odds ratios $(\mathrm{OR})$ for back injury from frequency of patient transfers among the total cohort of healthcare workers ( $N=5017)$. [95\% Cl=95\% confidence interval]

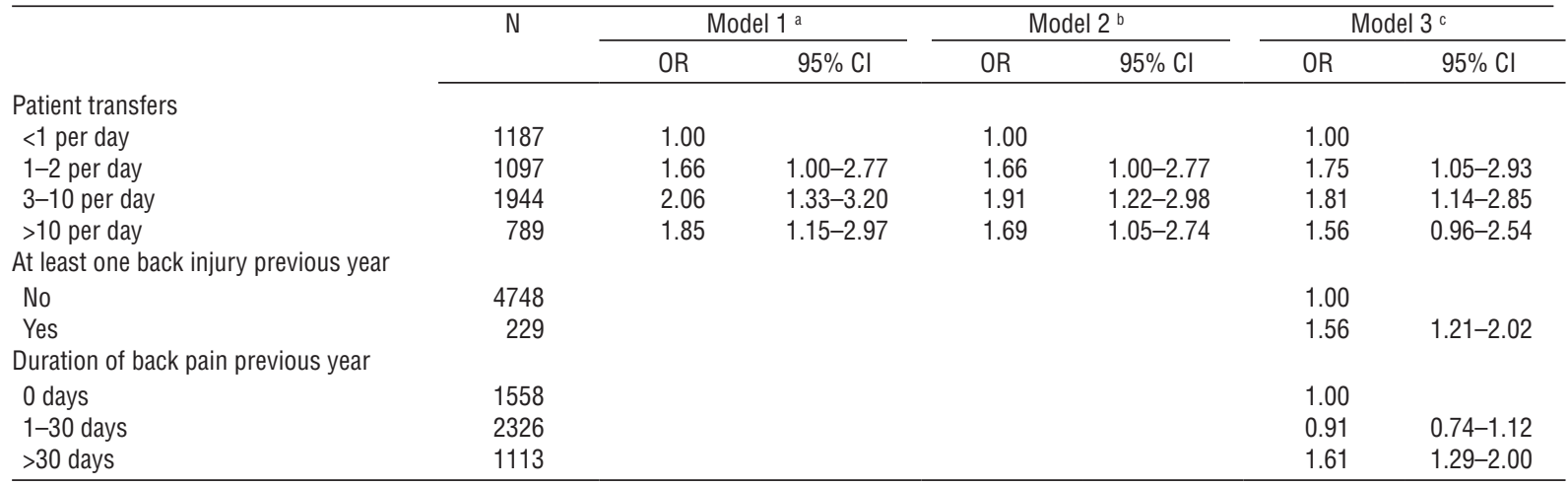

a Adjusted for age and lifestyle factors (body mass index, smoking, and leisure-time physical activity).

${ }^{b}$ Model 1 + adjusted for other work-related factor (seniority and influence at work).

${ }^{c}$ Model $2+$ estimates for back injury and back pain previous year at baseline.

Table 3. Odds ratios (OR) for accidental back injury from use of assistive device and transferring patients alone among healthcare workers with daily patient transfer $(\mathrm{N}=3820)$. [95\% $\mathrm{Cl}=95 \%$ confidence interval]

\begin{tabular}{|c|c|c|c|c|c|c|c|}
\hline & \multirow[t]{2}{*}{$\mathrm{N}$} & \multicolumn{2}{|c|}{ Model $1^{\text {a }}$} & \multicolumn{2}{|c|}{ Model $2^{b}$} & \multicolumn{2}{|c|}{ Model $3^{c}$} \\
\hline & & $\mathrm{OR}$ & $95 \% \mathrm{Cl}$ & OR & $95 \% \mathrm{Cl}$ & $\mathrm{OR}$ & $95 \% \mathrm{Cl}$ \\
\hline \multicolumn{8}{|c|}{ Use of assistive device } \\
\hline Sometimes & 790 & 1.00 & & 1.00 & & 1.00 & \\
\hline Often & 1178 & 0.56 & $0.34-0.92$ & 0.55 & $0.34-0.92$ & 0.59 & $0.36-0.98$ \\
\hline Very often & 1852 & 0.60 & $0.37-0.96$ & 0.60 & $0.37-0.97$ & 0.62 & $0.38-1.00$ \\
\hline \multicolumn{8}{|c|}{ Transferring patients alone } \\
\hline Never & 1192 & 1.00 & & 1.00 & & 1.00 & \\
\hline Seldom & 1273 & 0.85 & $0.57-1.27$ & 0.91 & $0.61-1.36$ & 0.93 & $0.62-1.41$ \\
\hline Sometimes & 1355 & 1.13 & $0.78-1.65$ & 1.15 & $0.78-1.68$ & 1.09 & $0.74-1.59$ \\
\hline \multicolumn{8}{|c|}{ Patient transfers } \\
\hline $1-2$ per day & 1097 & 1.00 & & 1.00 & & 1.00 & \\
\hline $3-10$ per day & 1944 & 1.12 & $0.91-1.39$ & 1.09 & $0.87-1.35$ & 1.07 & $0.86-1.33$ \\
\hline$>10$ per day & 789 & 1.05 & $0.81-1.37$ & 1.03 & $0.79-1.35$ & 0.98 & $0.74-1.28$ \\
\hline \multicolumn{8}{|c|}{ At least one back injury previous year } \\
\hline No & 3592 & & & & & 1.00 & \\
\hline Yes & 190 & & & & & 1.62 & $1.23-2.13$ \\
\hline \multicolumn{8}{|c|}{ Duration of back pain previous year } \\
\hline 0 days & 1119 & & & & & 1.00 & \\
\hline $1-30$ days & 1791 & & & & & 0.97 & $0.77-1.21$ \\
\hline$>30$ days & 882 & & & & & 1.56 & $1.22-2.00$ \\
\hline
\end{tabular}

${ }^{a}$ Adjusted for age, lifestyle factors (body mass index, smoking, and leisure-time physical activity) and frequency of patients transfer.

${ }^{\mathrm{b}}$ Model $1+$ adjustment for other work-related factors (tenure and influence at work).

c Model $2+$ estimates for back injury and back pain previous year.

extent be explained by differences in case definitions and reporting behaviors. In the present study, we asked specifically about back injury in relation to accident at work (ie, sudden onset episodes). By contrast, in the US the Bureau of Labor Statistics reflect "non-fatal occupational injury and illness cases requiring days away from work", making it difficult to distinguish between sudden onset episodes and more chronic types of pain. Thus, the case definition used in the present study allowed us to study risk factors for sudden onset episodes of back pain specifically.

\section{Frequency of patient transfers and risk of back injury}

We found increased risk of back injury among those performing daily patient transfer (table 2). In the model adjusted for lifestyle and work-related factors, as little as 1-2 transfers per day were associated with $66 \%$ increased risk of back injury. The risk was further increased among those performing 3-10 transfers per day, indicating a positive association between exposure and risk of injury as also supported by the trend test. However, among those with $>10$ transfers per day, the risk was approximately the same as for less frequent 
transfers and became only borderline significant compared with the reference group in the fully adjusted model. Overall these results suggest that any frequency of daily transfers is a risk factor for back injury, supporting the rationale for "no lifting" policies previously suggested in other studies.

The OR also decreased when adjusting for seniority and influence at work. These confounders were entered in model 2 as continuous variables and showed P-values of 0.07 and 0.01 , respectively (not shown in table 2), suggesting that more experienced workers with the ability to plan and influence work tasks may have decreased risk for back injury. This is in line with both Canadian and US studies reporting decreased risk of back injury among healthcare workers with longer seniority (16, 27). Thus, experienced workers may have acquired better skills and patient handling technique to protect against injuries than younger workers. They may also have greater influence to select less strenuous tasks than the younger workers. In addition, the "healthy worker" effect may influence these findings in that healthcare workers who are able to avoid severe injuries may have a higher probability of staying longer in the occupation and thus achieving a higher level of seniority.

\section{Use of assistive devices and risk of back injury}

Among healthcare workers with daily patient transfer, persistent use of an assistive device was associated with reduced risk of back injury (table 3, OR 0.59-0.62). This supports results from Australian and US studies showing up to $44 \%$ reduced numbers of back injury claims after implementation of "no lifting" or "minimal manual lifting" policies, eg, by using assistive devices during patient transfer $(15,16)$. In a study by Garg and Kapellusch (17), a more comprehensive participatory ergonomics program - including several aspects such as a "no manual lifting" policy, management commitment, empowering ergonomics teams in selection and use of equipment, program training, compliance, and continuous improvement - in seven nursing facilities in the US resulted in $60 \%$ fewer patient-handling injuries $2-5$ years later (17). An observational study across 23 US states showed that safe lift programs in healthcare facilities - endorsed and promoted by directors of nursing - reduced injury compensation claims frequency and costs (28). Altogether, these studies suggest that promotion and use of assistive devices during patient handling can reduce the risk for back injury.

By contrast, a Cochrane systematic review of randomized controlled trials (RCT) found moderate quality evidence that training on proper lifting techniques and use of assistive devices does not prevent back pain (29). Although back pain and back injuries may not always be caused by the same exposures, the findings of the
Cochrane review are still interesting in the context of the present study. One challenge of RCT is the lack of adherence to the intended intervention, which may have influenced the findings of the review. There exist many barriers towards implementing persistent and proper use of assistive device at the workplaces. Kurowski and coworkers (30) investigated this in a large US nursing home corporation and found that implementation of a safe-resident-handling program was most likely to succeed in conditions of low staff turnover and time pressure, and better teamwork, communication between staff, and support from leaders (30). Thus, healthcare workplaces should consider these supporting circumstances when implementing ergonomic programs to reduce the risk of back injury, and researchers should consider this as part of a multidisciplinary approach in future RCT.

\section{Incidence and recurrence of back injury}

The majority of back injuries during the follow-up period were new incidences, ie, $3.4 \%$ incidences and only $0.5 \%$ recurrences. This explains why adjusting for previous back injury and pain in the model for patient transfer only changed the estimates slightly $(\sim 0.1$ in either direction). In spite of this, both previous back injury and $>30$ days with back pain during the previous year were associated with an increased risk of back injury during follow-up with OR of 1.56 and 1.60 , respectively. This shows that even when recurrence is very low, prevention of recurrence or secondary low back pain is important in the return-to-work process for injured workers $(8,31)$.

\section{Limitations}

Our study has both strengths and limitations. The large sample size of female healthcare workers in eldercare from 36 different municipalities across Denmark strengthens the validity of the estimates for this specific occupational group. Considering that our results support studies using different sampling strategies and from other parts of the world - likely with different cultures, education systems, physical and psychosocial work environments, and types of available assistive devices - stresses the generalizability of the findings. However, asking in retrospect about back injuries during the last year related to patient transfers may have underestimated the true prevalence due to recall bias. However, using claims data, as in studies from many other countries, may also be biased because the worker has an economic incentive to report back injuries whether the pain is actually related to a specific accident at work or not. Future studies may incorporate other systems not prone to bias from retrospective registration or economic incentives, 
eg, anonymous weekly text messaging (SMS) tracking of injuries unrelated to claim systems. Furthermore, the question used in the present study asked about injuries occurring during a sudden and unexpected event, but not whether the pain symptoms were of sudden onset. In hindsight, asking whether the pain symptoms were of sudden onset during the injury and what the healthcare worker was doing at that exact moment could provide additional information. We adjusted the analyses for several confounders; age, BMI, smoking status, leisuretime physical activity, previous back injury and back pain, seniority, and influence at work. However, we did not adjust the analyses for psychological risk factors for musculoskeletal pain such as somatizing tendencies (32) because such factors are probably more relevant in relation to chronic disabling pain than to injuries with acute onset. The subjective nature of both exposure and outcome is a weakness of our study due to common-rater effects (33). Thus, in spite of the large associated cost, future studies should use either objective registrations of exposure (eg, by observations) or clinical examinations for the outcome.

In conclusion, daily patient transfer is a risk factor for back injury among healthcare workers in eldercare. Persistent use of an assistive device was associated with reduced risk for back injury among healthcare workers with daily patient transfers.

\section{Acknowledgments}

The authors thank the coworkers from the Danish Health Care Worker Cohort (DHCWC) 2004 study group for their contribution to data collection.

\section{References:}

1. Tullar JM, Brewer S, Amick BC, III, Irvin E, Mahood Q, Pompeii LA, et al. Occupational safety and health interventions to reduce musculoskeletal symptoms in the health care sector. J Occup Rehabil. 2010 Jun;20(2):199-219. http://dx.doi. org/10.1007/s10926-010-9231-y.

2. European Commission. European Commission Occupational health and safety risks in the healthcare sector. Luxembourg: Luxembourg, 2011.

3. Andersen LL, Clausen T, Burr H, Holtermann A. Threshold of musculoskeletal pain intensity for increased risk of longterm sickness absence among female healthcare workers in eldercare. PLoS One. 2012;7(7):e41287. http://dx.doi. org/10.1371/journal.pone.0041287.

4. Bureau of Labor Statistics (BLS). BLS News Release. Washington DC (USA): US Department of Labor, 2011.
5. Pransky G, Benjamin K, Hill-Fotouhi C, Himmelstein J, Fletcher KE, Katz JN, et al. Outcomes in work-related upper extremity and low back injuries: results of a retrospective study. Am J Ind Med. 2000 Apr;37(4):400-9. http://dx.doi. org/10.1002/(SICI)1097-0274(200004)37:4<400::AIDAJIM10>3.0.CO;2-C .

6. Engkvist IL, Hagberg M, Hjelm EW, Menckel E, Ekenvall L. The accident process preceding overexertion back injuries in nursing personnel. PROSA study group. Scand J Work Environ Health. 1998 Oct;24(5):367-75. http://dx.doi.org/10.5271/ sjweh.357.

7. Byrns G, Reeder G, Jin G, Pachis K. Risk factors for work-related low back pain in registered nurses, and potential obstacles in using mechanical lifting devices. J Occup Environ Hyg. 2004 Jan;1(1):11-21. http://dx.doi. org/10.1080/15459620490249992.

8. Smedley J, Egger P, Cooper C, Coggon D. Prospective cohort study of predictors of incident low back pain in nurses. BMJ. 1997 Apr 26;314(7089):1225-8. http://dx.doi.org/10.1136/ bmj.314.7089.1225.

9. Retsas A, Pinikahana J. Manual handling activities and injuries among nurses: an Australian hospital study. J Adv Nurs. 2000 Apr;31(4):875-83. http://dx.doi.org/10.1046/j.13652648.2000.01362.x.

10. Skotte JH, Essendrop M, Hansen AF, Schibye B. A dynamic 3D biomechanical evaluation of the load on the low back during different patient-handling tasks. J Biomech. 2002 Oct;35(10):1357-66. http://dx.doi.org/10.1016/S00219290(02)00181-1.

11. Marras WS, Davis KG, Kirking BC, Bertsche PK. A comprehensive analysis of low-back disorder risk and spinal loading during the transferring and repositioning of patients using different techniques. Ergonomics. 1999 Jul;42(7):90426. http://dx.doi.org/10.1080/001401399185207.

12. Ruseckaite R, Collie A. Repeat workers' compensation claims: risk factors, costs and work disability. BMC Public Health. 2011;11:492. http://dx.doi.org/10.1186/1471-2458-11-492.

13. Lipscomb HJ, Cameron W, Silverstein B. Incident and recurrent back injuries among union carpenters. Occup Environ Med. 2008 Dec;65(12):827-34. http://dx.doi. org/10.1136/oem.2008.039222.

14. Wasiak R, Kim J, Pransky G. Work disability and costs caused by recurrence of low back pain: longer and more costly than in first episodes. Spine (Phila Pa 1976). 2006 Jan 15;31(2):219-25.

15. Martin PJ, Harvey JT, Culvenor JF, Payne WR. Effect of a nurse back injury prevention intervention on the rate of injury compensation claims. J Safety Res. 2009;40(1):13-9. http:// dx.doi.org/10.1016/j.jsr.2008.10.013.

16. Schoenfisch AL, Lipscomb HJ, Pompeii LA, Myers DJ, Dement JM. Musculoskeletal injuries among hospital patient care staff before and after implementation of patient lift and transfer equipment. Scand J Work Environ Health. 2013 Jan;39(1):27-36. http://dx.doi.org/10.5271/sjweh.3288.

17. Garg A, Kapellusch JM. Long-term efficacy of an ergonomics program that includes patient-handling devices 
on reducing musculoskeletal injuries to nursing personnel. Hum Factors. 2012 Aug;54(4):608-25. http://dx.doi. org/10.1177/0018720812438614.

18 The National Committee on Health Research Ethics (DNVK). Guidelines about Notification. Committee System on Biomedical Research Ethics. Copenhagen: DNVK, 2011. Available from: http://www.dnvk.dk/English/ guidelinesaboutnotification.aspx.

19. The Danish Data Protection Agency. Standard terms for research projects - AUTHORISATION to process personal data. Copenhagen: The Danish Data Protection Agency, 2008. Available from: http://www.datatilsynet.dk/erhverv/ forskere-og-medicinalfirmaer/standard-terms-for-researchprojects/

20. Holtermann A, Clausen T, Jorgensen MB, Burdorf A, Andersen LL. Patient handling and risk for developing persistent low-back pain among female healthcare workers. Scand J Work Environ Health. 2013 Mar ;39(2):164-9. http://dx.doi. org/10.5271/sjweh.3329.

21. Kuorinka I, Jonsson B, Kilbom Å, Vinterberg H, BieringSørensen F, Andersson G, et al. Standardised Nordic questionnaires for the analysis of musculoskeletal symptoms. Appl Ergo. 1987;18(3):233-7. http://dx.doi. org/10.1016/0003-6870(87)90010-X.

22. Andersen LL, Clausen T, Mortensen OS, Burr H, Holtermann A. A prospective cohort study on musculoskeletal risk factors for long-term sickness absence among healthcare workers in eldercare. Int Arch Occup Environ Health. 2012 Aug;85(6):615-22. http://dx.doi.org/10.1007/s00420-0110709-5.

23. Saltin B, Grimby G. Physiological analysis af middle-aged and old former athletes. Circulation. 1968;38:1104-15. http:// dx.doi.org/10.1161/01.CIR.38.6.1104.

24. Clausen T, Nielsen K, Carneiro IG, Borg V. Job demands, job resources and long-term sickness absence in the Danish eldercare services: a prospective analysis of register-based outcomes. J Adv Nurs. 2011 Jun 9;68(1):127-36. http://dx.doi. org/10.1111/j.1365-2648.2011.05724.x.

25. Pejtersen JH, Kristensen TS, Borg V, Bjorner JB. The second version of the Copenhagen Psychosocial Questionnaire. Scand J Public Health. 2010 Feb;38(3 Suppl):8-24. http://dx.doi. org/10.1177/1403494809349858.
26. Burdorf A, Koppelaar E, Evanoff B. Assessment of the impact of lifting device use on low back pain and musculoskeletal injury claims among nurses. Occup Environ Med. 2013 Jul;70(7):491-7. http://dx.doi.org/10.1136/ oemed-2012-101210.

27. Yassi A, Khokhar J, Tate R, Cooper J, Snow C, Vallentyne $\mathrm{S}$. The epidemiology of back injuries in nurses at a large Canadian tertiary care hospital: implications for prevention. Occup Med. 1995;45(4):215-20. http://dx.doi.org/10.1093/ occmed/45.4.215.

28. Restrepo TE, Schmid FA, Gucer PW, Shuford HL, Shyong CJ, McDiarmid MA. Safe lifting programs at long-term care facilities and their impact on workers' compensation costs. J Occup Environ Med. 2013 Jan;55(1):27-35. http://dx.doi. org/10.1097/JOM.0b013e318270d535.

29. Verbeek JH, Martimo KP, Karppinen J, Kuijer PP, ViikariJuntura E, Takala EP. Manual material handling advice and assistive devices for preventing and treating back pain in workers. Cochrane Database Syst Rev. 2011;(6):CD005958.

30. Kurowski A, Gore R, Buchholz B, Punnett L. Differences among nursing homes in outcomes of a safe resident handling program. J Health Risk Manag. 2012;32(1):35-51. http:// dx.doi.org/10.1002/jhrm.21083.

31. van Poppel MN, Koes BW, Deville W, Smid T, Bouter LM. Risk factors for back pain incidence in industry: a prospective study. Pain. 1998 Jul;77(1):81-6. http://dx.doi.org/10.1016/ S0304-3959(98)00085-2.

32. Palmer KT, Calnan M, Wainwright D, Poole J, O’Neill C, Winterbottom A, et al. Disabling musculoskeletal pain and its relation to somatization: a community-based postal survey. Occup Med (Lond). 2005 Dec;55(8):612-7. http://dx.doi. org/10.1093/occmed/kqi142.

33. Podsakoff PM, Mackenzie SB, Podsakoff NP. Sources of method bias in social science research and recommendations on how to control it. Annu Rev Psychol. 2012 Jan 10;63:539-69. http://dx.doi.org/10.1146/annurev-psych-120710-100452.

Received for publication: 2 April 2013. 